\title{
Preparation and Properties of Biocomposite Based on Natural Rubber and Bagasse Nanocellulose
}

\author{
Methakarn Jarnthong ${ }^{1, \mathrm{a}}$, Fei Wang ${ }^{1, \mathrm{~b}}$, Xiao Yi Wei ${ }^{1, \mathrm{c}}$, Rui Wang ${ }^{1, \mathrm{~d},}$ Ji Hua Li ${ }^{1, \mathrm{e}}$ \\ ${ }^{1}$ Key Laboratory of Tropical Crop Products Processing of Ministry of Agriculture, Agriculture Products Processing Research Institute, \\ Chinese Academy of Tropical Agricultural Sciences, Zhanjiang 524001, China
}

\begin{abstract}
Biocomposite based on natural rubber (NR) and bagasse nanocellulose (BNC) was prepared in latex state. The mechanical, morphological and thermal properties of NR/BNC biocomposite were investigated. It was found that the addition of $3 \mathrm{wt} \%$ of BNC in NR film caused significant increase in modulus at $100 \%$ and $300 \%$ elongations and improved thermal stability of NR/BNC biocomposite. However, the strength at break and elongation at break of the biocomposite were not enhanced correlating to the morphological result obtained from scanning electron microscope (SEM).
\end{abstract}

\section{Introduction}

In recent years, biocomposites have received much attention to replace petrochemical based materials because the environmental awareness and the international demand for green technology. Extensive work has been done to incorporate natural fiber into polymer matrix to develop sustainable materials which meet up the recent demand of lightweight composites with high specific strength and modulus. Bagasse fiber is one of natural fibers made from by-product of sugar cane industry. There have been a number of researches exploring the use of bagasse fiber to reinforce natural rubber [1-3]. They found that the addition of bagasse fiber in natural rubber matrix improved tensile strength and barrier properties and increased rate of degradation of the rubber in soil. In this work, another form of bagasse fiber, the bagasse nanocellulose (BNC) powder, was used to reinforce natural rubber film. The properties of $\mathrm{NR} / \mathrm{BNC}$ biocomposite including mechanical, morphological and thermal properties were investigated.

\section{Experimental}

\subsection{Materials}

High ammonia (HA) natural rubber concentrated latex with $60 \%$ of dry rubber content was supplied by the Key Laboratory of Ministry of Agriculture for Natural Rubber Processing Zhanjiang, China. The bagasse nanocellulose (BNC) powder with particle size range of 5-12 nm was extracted from bagasse cellulose by high pressure homogenization (HPH) according to the method described elsewhere [4]. The BNC powder was dried at $50^{\circ} \mathrm{C}$ for $24 \mathrm{~h}$ in hot air oven before used to remove moisture. Characterization of unmodified bagasse nanocellulose was accomplished by FTIR spectroscopy as shown in Fig. 1.

\subsection{Preparation of NR/BNC biocomposite}

Natural rubber biocomposite reinforced with $3 \mathrm{wt} \%$ of bagasse nanocellulose was prepared in latex stage. The BNC powder was first dispersed in DI water and sonicated for $30 \mathrm{~min}$. NR latex and the suspension of BNC were mixed by using magnetic stirrer for $2 \mathrm{~h}$ at room temperature. The mixture was cast in Teflon mold and then left at room temperature for $48 \mathrm{~h}$. After that, the $\mathrm{NR} / \mathrm{BNC}$ film was dried in vacuum oven at $50^{\circ} \mathrm{C}$ for another $48 \mathrm{~h}$ to obtain final dry film around $1 \mathrm{~mm}$ thick.

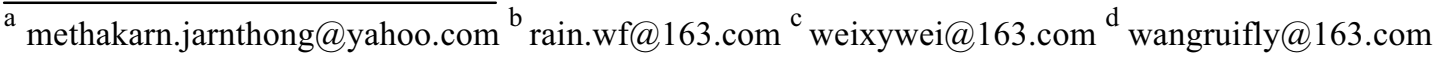

efoodpaper@126.com
} 


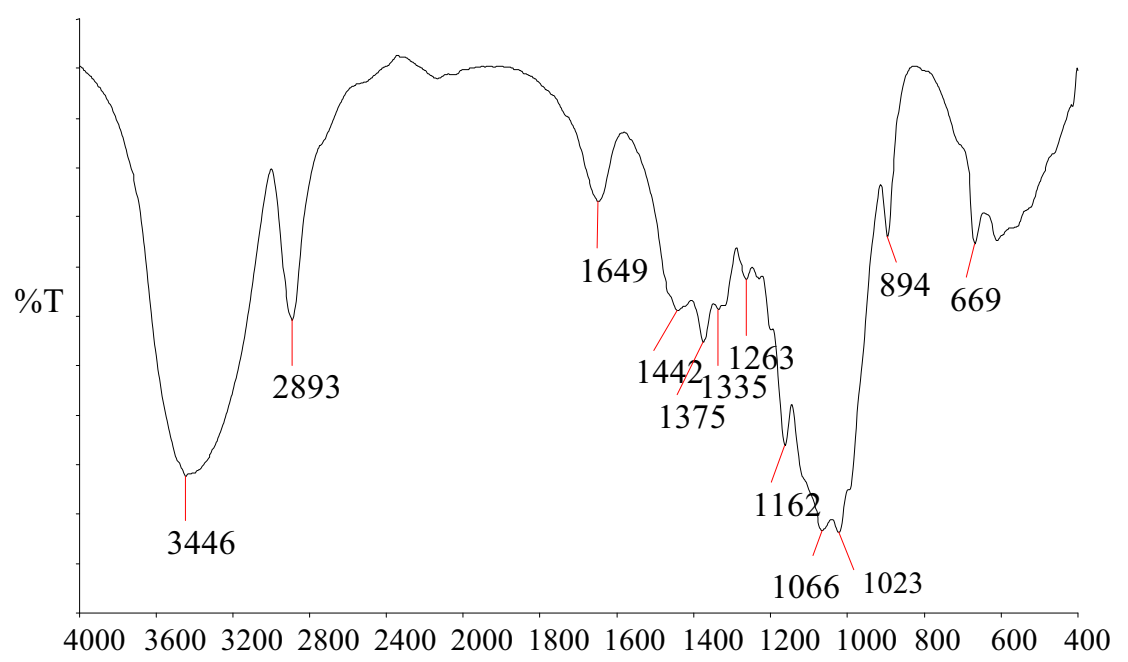

Figure. 1. FTIR spectrum of bagasse nanocellulose

\subsection{Measurement}

The mechanical properties of dried film were analyzed by Hounsfield H10KS universal testing machine based on ASTM D412 at a crosshead speed of $500 \mathrm{~mm} / \mathrm{min}$ using five samples. Scanning electron microscope (SEM) (Philips XL 30-EDAX microscope) was used to study the morphology of cross-sectional sample. The sample was frozen under liquid nitrogen, fractured, coated with gold/palladium and observed using an accelerating voltage of $1.0 \mathrm{kV}$. Thermogravimetric analysis (TGA) was carried out using a Perkin Elmer (TGA7) instrument, in $\mathrm{N} 2$ atmosphere at $10^{\circ} \mathrm{C} / \mathrm{min}$ heating rate, from 30 to $650^{\circ} \mathrm{C}$.

\section{Results and discussion}

\subsection{Mechanical properties of NR/BNC}

Mechanical properties of unvulcanized NR films with and without $3 \mathrm{wt} \% \mathrm{BNC}$ were investigated by tensile test at room temperature. The stress-strain curves of NR and NR/BNC films are shown in Fig. 2. The median values of moduli at $100 \%$ and $300 \%$ elongations, tensile strength and elongation at break are reported in Table 1.

Fig. 2 shows stress-strain curves of natural rubber and bagasse nanocellulose filled natural rubber films without vulcanization. It can be seen that the incorporation of unmodified bagasse nanocellulose particles in the natural rubber increaseed the initial stress, which indicated increasing of stiffness.

Table 1. Mechanical properties of uncured NR and NR/BNC biocomposite.

\begin{tabular}{lcccc}
\hline Samples & $\begin{array}{c}\text { M100 } \\
(\mathbf{M P a})\end{array}$ & $\begin{array}{c}\text { M300 } \\
(\mathbf{M P a})\end{array}$ & $\begin{array}{c}\text { Tensile strength } \\
(\mathbf{M P a})\end{array}$ & Elongation at break (\%) \\
\hline $\mathrm{NR}$ & 0.33 & 0.36 & 1.16 & 915 \\
$\mathrm{NR} / \mathrm{BNC}$ & 0.47 & 0.53 & 1.11 & 793 \\
\hline
\end{tabular}

Table 1 shows the tensile moduli at $100 \%$ and $300 \%$ elongations, tensile strength and elongation at break of $\mathrm{NR}$ and NR/BNC biocomposite. It can be clearly seen that the incorporation of BNC particles increased tensile modulus of natural rubber. It is noted that tensile modulus refers to the stiffness or ability of materials to resist the deformation. Therefore, addition of stiff particles into the soft polymer matrix markedly improves in stiffness of the filled system [5]. However, tensile strength of the composite slightly decreased with the presence of BNC particles. This can be explained due to poor dispersion of the BNC particles in the NR matrix. Hydroxyl groups on surface of unmodified BNC particles (appearing at wavenumbers of 3446 and $669 \mathrm{~cm}^{-1}$ as shown in Fig. 1) exhibited strong hydrophilic nature. Therefore, the hydrophilic BNC particles could not disperse well in hydrophobic natural rubber matrix as proven by SEM result shown in Fig. 3. 


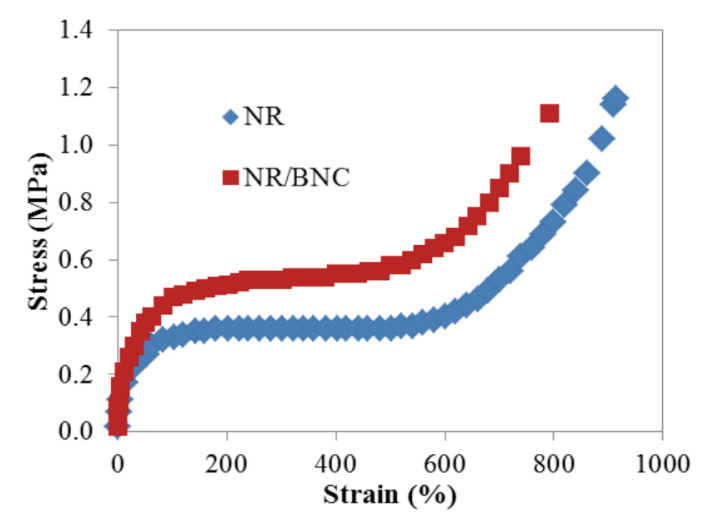

Figure. 2. Typical stress-strain curves of uncured NR and NR/BNC composite

\subsection{Morphological property}

As seen in Fig. 3(A) and (B), the SEM micrographs of BNC powder show spherical shape with diameters 100$200 \mathrm{~nm}$. However, the nanoparticles are gathered together to form large agglomerated particles. This is due to the functional groups on surface of unmodified BNC tended to agglomerate through hydrogen bonding. The formation of agglomerates in NR matrix (Fig. 3(C)) caused additional stress concentrators leading to increased chances of failure, which finally reduced tensile strength and elongation at break of the biocomposite.

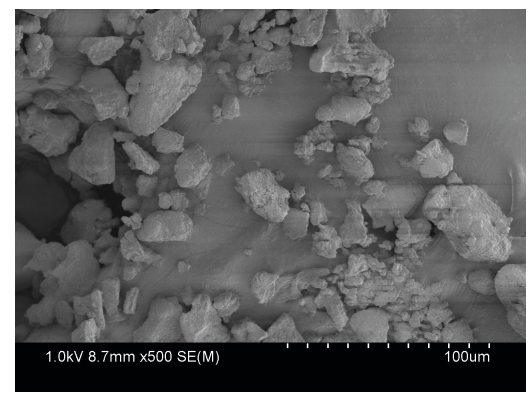

(A)

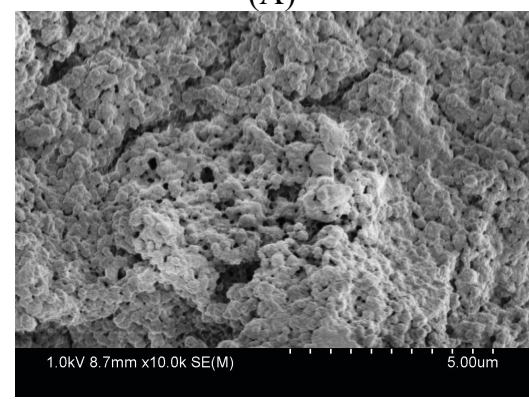

(B)

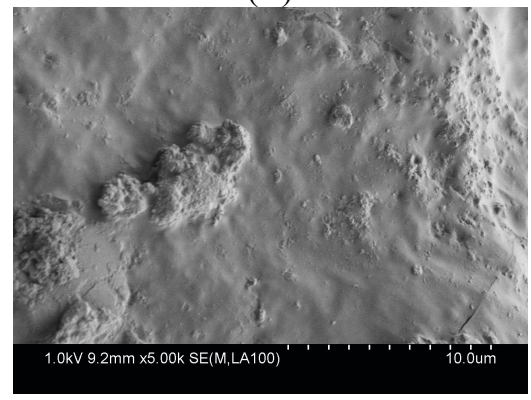

(C)

Figure. 3. Morphology of bagasse nanocellulose (A: 500x and B: 10000x) and fractured surface of NR/BNC biocomposite.

\subsection{Thermal properties}

Fig. 4 shows the TGA and DTG curves, respectively, of $\mathrm{NR}, \mathrm{BNC}$ and NR/BNC biocomposites. The thermal decomposition of $\mathrm{BNC}$ consisted of two decomposition steps. The first stage of decomposition was the evaporation of absorbed moisture in the cellulose. The second stage of decomposition corresponded to the main decomposition of the nanocellulose [4]. The DTG curves showed that $\mathrm{BNC}$ was maximum degraded at the temperatures of $337.6^{\circ} \mathrm{C}$. NR and NR/BNC show onestep decomposition process and the maximum decomposition was given at 374.5 and $376.6^{\circ} \mathrm{C}$, respectively. From DTG curve, the decomposition rate of NR/BNC reduced comparing with NR. This can be attributed that the incorporation of $3 \mathrm{wt} \%$ of $\mathrm{BNC}$ in $\mathrm{NR}$ increased thermal stability of NR matrix.

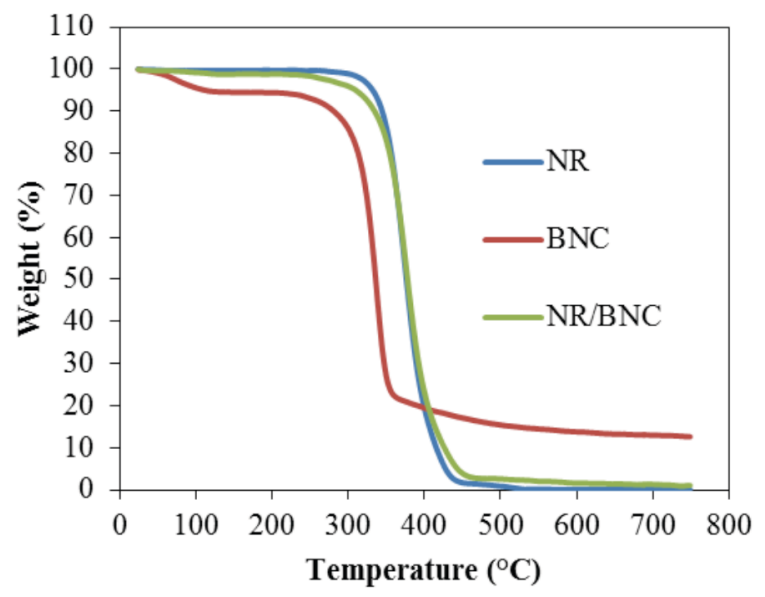

(A)

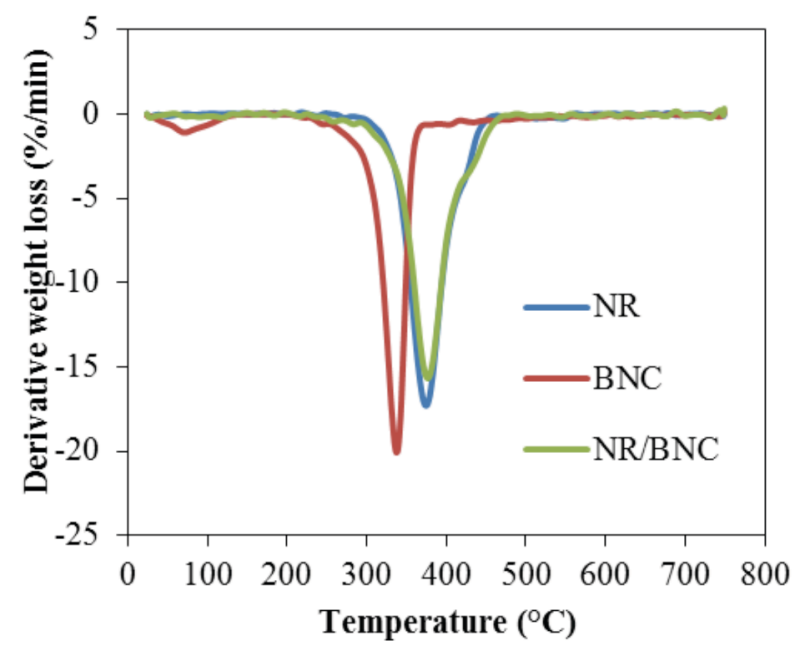

(B)

Figure. 4. Thermogravimetric analysis (TGA) (A) and derivative thermogravimetric (DTG) (B) curves for NR, BNC and NR/BNC.

\section{Summary}

Biocomposite of natural rubber and bagasse nanocellulose was successfully prepared in latex stage. The addition of $3 \mathrm{wt} \%$ of nanocellulose in natural rubber enhanced modulus and thermal stability of the rubber matrix. However, the agglomeration of bagasse 
nanocellulose caused the reduction of tensile strength and elongation at break of natural rubber. This is due to the incompatible between hydrophilic surface of bagasse nanocellulose and hydrophobic natural rubber. To solve this problem, our further work will focus on surface modification of bagasse nanocellulose.

\section{Acknowledgments}

This work was financially supported by the Fundamental Scientific Research Funds for Chinese Academy of Tropical Agricultural Sciences (project numbers 1630062013012 and 1630022013020).

\section{References}

1. J. Bras, M.I. Hassan, C. Bruzesse, E.A. Hassan, N.A. El-Wakil, A. Dufresne, Ind. Crop. Prod. 32 (2010) 627-633.

2. S. Kanking, P. Niltui, E. Wimolmala, N. Sombatsompop, Mater. Des. 41 (2012) 74-82.

3. D. Pasquini, E.d.M. Teixeira, A.A.d.S. Curvelo, M.N. Belgacem, A. Dufresne. Ind. Crop. Prod. 32 (2010) 486-490.

4. J. Li, X. Wei, Q. Wang, J. Chen, G. Chang, L. Kong, Carbohydr. Polym. 90 (2012) 1609-1613..

5. S.Y. Fu, X.Q. Feng, B. Lauke, Y.W. Mai, Compos. Part B: Eng 39 (2008) 933-961. 